\title{
Profiling of Expression of Human Papillomavirus-Related Cancer miRNAs in Penile Squamous Cell Carcinomas
}

\author{
Luisa Barzon, ${ }^{*}$ Rocco Cappellesso, ${ }^{\dagger}$ Elektra Peta, ${ }^{*}$ Valentina Militello, ${ }^{*}$ Alessandro Sinigaglia, ${ }^{*}{ }^{\star}$ Matteo Fassan, \\ Francesca Simonato, ${ }^{\dagger}$ Vincenza Guzzardo, ${ }^{\dagger}$ Laura Ventura, ${ }^{\top}$ Stella Blandamura, ${ }^{\dagger}$ Marina Gardiman, ${ }^{\dagger}$ Giorgio Palù, ${ }^{*}$ and \\ Ambrogio Fassina
}

From the Departments of Molecular Medicine, ${ }^{*}$ Medicine, ${ }^{\dagger}$ and Statistical Sciences, ${ }^{\complement}$ University of Padua, Padua; the Virology Unit, ${ }^{\ddagger}$ Parma University Hospital, Parma; and the Veneto Region Oncology Institute (Istituto Oncologico Veneto-IRCCS), ${ }^{\S}$ Padua, Italy

Accepted for publication August 14, 2014.

Address correspondence to Ambrogio Fassina, M.D., Department of Medicine (DIMED), Surgical Pathology \& Cytopathology Unit, University of Padua, Via Aristide Gabelli 61, 35121 Padua, Italy. E-mail: ambrogio. fassina@unipd.it.

\begin{abstract}
Penile squamous cell carcinoma (PSCC) is a rare tumor associated with high-risk human papillomavirus (HR-HPV) infection in $30 \%$ to $60 \%$ of cases. Altered expression of miRNAs has been reported in HPVrelated cervical and head and neck cancers, but such data have not been available for PSCC. We analyzed a series of 59 PSCCs and 8 condylomata for presence of HPV infection, for p16 $6^{\text {INK4a }}$, Ki-67, and p53 immunohistochemical expression, and for expression of a panel of cellular miRNAs (let-7c, miR-23b, miR-34a, miR-145, miR-146a, miR-196a, and miR-218) involved in HPV-related cancer. HR-HPV DNA (HPV16 in most cases) was detected in 17/59 (29\%) PSCCs; all penile condylomata (8/8) were positive for low-risk HPV6 or HPV11. HR-HPV ${ }^{+}$PSCCs overexpressed $\mathrm{p} 16^{\text {INK4a }}$ in $88 \%$ cases and $\mathrm{p} 53$ in $35 \%$ of cases, whereas HR-HPV ${ }^{-}$PSCCs were positive for $\mathrm{p}^{16^{\mathrm{INK}} 4 \mathrm{a}}$ and $\mathrm{p} 53$ immunostaining in $9 \%$ and $44 \%$ of cases, respectively. Among the miRNAs investigated, expression of miR-218 was lower in PSCCs with

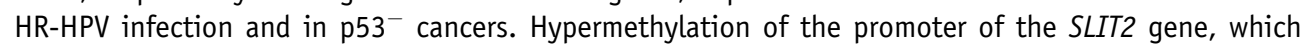
contains miR-218-1 in its intronic region, was frequently observed in PSCCs, mainly in those with low miR-218 expression. Epigenetic silencing of miR-218 is a common feature in HR-HPV PSCCs and in HRHPV $^{-}$PSCCs without immunohistochemical detection of p53. (Am J Pathol 2014, 184: 3376-3383; http://dx.doi.org/10.1016/j.ajpath.2014.08.004)
\end{abstract}

Penile squamous cell carcinoma (PSCC) is a relatively rare cancer that usually originates in the epithelium of the inner prepuce and glans. ${ }^{1}$ It accounts for less than $0.5 \%$ of cancers in men in Western countries and for approximately $10 \%$ of cancers in men in high-incidence countries of South America and Africa. ${ }^{1}$ Mortality, however, is low. HPV DNA is detectable in $30 \%$ to $60 \%$ of all invasive PSCCs, and prevalence varies across different series. ${ }^{2-4}$ The presence of HPV infection strongly correlates with either mixed basaloid and verrucous or purely basaloid histotype and is only weakly associated with the usual type of keratinizing SCC. ${ }^{2-4}$ HPV 16 and, to a lesser extent, HPV18 are the most frequent viral types associated with PSCC; HPV31 and HPV33 are rarely detected. ${ }^{2-4}$

The mechanisms of HPV oncogenesis have been extensively investigated in cervical cancer, but only limited data are available for PSCC. Oncogenic HPV types cause cancer mainly by inducing degradation of the tumor suppressor proteins p53 and pRb (by E6 and E7 viral proteins, respectively), but also important are alterations of additional pathways involved in regulation of cell-cycle progression, telomere maintenance, apoptosis, chromosomal stability, and cell adhesion and migration. ${ }^{5}$ Recently, high-risk HPV (HRHPV) infection was reported in association with aberrant expression of oncogenic and tumor-suppressive host miRNAs. ${ }^{6}$ Most of these miRNAs are deregulated via the E6-p53 and E7-pRb pathways, including such as miR-34a/ b/c, miR-23b, miR-145, and miR-218, which are downregulated by HR-E6, and miR-146a and the let-7 family of miRNAs, which are down-regulated by c-Myc (which in turn

Supported by a doctoral fellowship from the CaRiPaRo Foundation (E.P.) and by the Italian Ministry for Education, University, and Research (MIUR) grant 2010Z9FLM8 for reagents and consumables.

L.B. and R.C. contributed equally to this work.

Disclosures: None declared. 
is activated by both HR-E6 and HR-E7). ${ }^{6}$ Altered expression of these miRNAs has been reported in cervical and head and neck cancers, ${ }^{6}$ but there have been no previous studies on PSCC.

We investigated expression of a panel of cellular miRNAs involved in HPV-related cancer in a series of PSCCs and analyzed its relationship with the presence of HPV infection and with $\mathrm{p} 53$, Ki-67, and $\mathrm{p} 16^{\mathrm{INK} 4 \mathrm{a}}$ expression.

\section{Materials and Methods}

\section{Patients and Tissue Specimens}

The specimens studied were 59 formalin-fixed, paraffinembedded PSCC samples from patients who underwent surgical biopsy or resection (median age, 68 years; range, 44 to 87 years) and 8 condyloma samples as control (median age, 42 years; range, 26 to 60 years) retrieved from the archives of the Pathology Unit at the University of Padua, from January 2002 to December 2010. All diagnoses were based on World Health Organization criteria ${ }^{7}$ and were confirmed jointly by three masked pathologists (A.F., R.C., and M.F.). The study was approved (no. 0037713) by the Institutional Ethical Review Board of the University of Padua and was conducted in accord with the Institute's ethical regulations on research involving human tissues.

\section{Immunohistochemistry}

Automated immunohistochemistry staining (Leica Microsystems BOND-MAX; Menarini, Florence, Italy) was performed on 4- $\mu \mathrm{m}$ formalin-fixed, paraffin-embedded sections with primary antibodies for p53 (clone DO-7, prediluted; Dako, Glostrup, Denmark; Carpinteria, CA), p16 ${ }^{\mathrm{INK} 4 \mathrm{a}}$ (clone JC8, prediluted; Santa Cruz Biotechnology, Dallas, TX), and Ki-67 (clone SP6, dilution 1:200; Spring Bioscience, Pleasanton, CA), as described previously. ${ }^{8,9}$ Appropriate positive and negative controls were run concurrently. Three observers (A.F., R.C., and M.F.) independently scored protein expression and a consensus score was reached. p53 staining was defined as positive if $\geq 75 \%$ of the cells exhibited a strong nuclear staining (indicative of p53 accumulation due to mutation). For evaluation of $\mathrm{p} 16^{\mathrm{INK} 4 \mathrm{a}}$ expression, patterns of immunohistochemistry reactions were scored on a fourpoint scale: 0 , complete absence of $\mathrm{p} 16^{\mathrm{INK} 4 \mathrm{a}}$ staining in all neoplastic cells; 1 , staining only in isolated and dispersed neoplastic cells; 2 , staining in patchy and scattered clusters of neoplastic cells; and 3, dense and continuous cytoplasmic/ nuclear staining in all neoplastic cells (except hyperkeratotic or parakeratotic areas). ${ }^{10}$ In each tumor, the highest score was assumed to be representative of the whole lesion, and only score 3 was considered indicative of $\mathrm{p} 16^{\mathrm{INK} 4 \mathrm{a}}$ overexpression. ${ }^{10}$ Expression of Ki-67 was classified as weak if $\leq 15 \%$ of the neoplastic cells exhibited nuclear staining, intermediate if $15 \%$ to $60 \%$ of nuclei were positive, and strong if $>60 \%$ of nuclei were positive. ${ }^{11}$
Table 1 Primers Used for miRNA Real-Time Quantitative PCR with Reverse Transcription

\begin{tabular}{ll}
\hline miRNA & Forward primer \\
\hline hsa-let-7c & $5^{\prime}$-CGCTGAGGTAGTAGGTTGTATGGTT-3' \\
hsa-miR-23b & $5^{\prime}$-ATCACATTGCCAGGGATTACC-3' \\
hsa-miR-34a & $5^{\prime}$-GGCAGTGTCTTAGCTGGTTGT-3' \\
hsa-miR-145 & $5^{\prime}$-CAGTTTTCCCAGGAATCCCT-3' \\
hsa-miR-146a & $5^{\prime}$-TGAGAACTGAATTCCATGGGTT-3' \\
hsa-miR-196a & $5^{\prime}$-GCTAGGTAGTTTCATGTTGTTGGG-3' \\
hsa-miR-218 & $5^{\prime}$-CGTTGTGCTTGATCTAACCATGT-3' \\
RNU6B & $5^{\prime}$-ACGCAAATTCGTGAAGCGTT-3' \\
\hline
\end{tabular}

\section{DNA Purification, Detection of HPV DNA, and Genotyping}

From the corresponding significant non-necrotic areas of the slides (hematoxylin and eosin stain), 2-mm cores of tissue were microdissected from the paraffin block and deparaffinized in xylene for 3 minutes at $50^{\circ} \mathrm{C}$. Genomic DNA was extracted with a MagNA Pure 96 nucleic acid kit in a MagNA Pure 96 system (Roche Diagnostics, Mannheim, Germany; Indianapolis, IN) and was eluted in $100 \mu \mathrm{L}$, according to the manufacturer's recommendations. For PCR amplification and reverse hybridization, $5 \mu \mathrm{L}$ of the DNA solution was used with the INNO-LiPA HPV Genotyping Extra line probe assay (Innogenetics, Ghent, Belgium) for HPV detection and typing, as described previously. ${ }^{12}$ The presence of HPV types in all samples positive by the line probe assay was also investigated by type-specific quantitative real-time PCR (qPCR), which allowed estimation of the viral genome copy number per cell (ratio to the $\beta$-globin gene copy number), as described previously. ${ }^{13}$

\section{RNA Extraction and RT-qPCR Analysis of miRNAs}

Total RNA was extracted from tissue cores with an Ambion RecoverAll kit (Life Technologies, Carlsbad, CA), as described previously. $8,14,15$ To detect and quantify mature hsa-miR-145, hsa-miR-146a, hsa-miR-23b, hsa-miR-218, hsa-miR-196a, hsa-miR-34a, and hsa-let-7c, an NCode miRNA real-time quantitative PCR with reverse transcription (RT-qPCR) method (Life Technologies) was used on a LightCycler 480 real-time PCR system (Roche Diagnostics); results were normalized to the small nuclear RNA U6B (RNU6b assay; Life Technologies). Primer sequences are reported in Table 1. All reactions were run in triplicate, including no-template controls.

\section{Methylation Analysis of SLIT2 and SLIT3 Promoters}

Methylation analysis of the SLIT2 and SLIT3 promoters was performed by treatment of genomic DNA with bisulfite using an EpiTect bisulfite kit (Qiagen, Hilden, Germany; Valencia, CA) followed by PCR amplification with methylationsensitive primers, as described previously. ${ }^{16}$ Sequence analysis of PCR amplicons was performed by cycle sequencing 


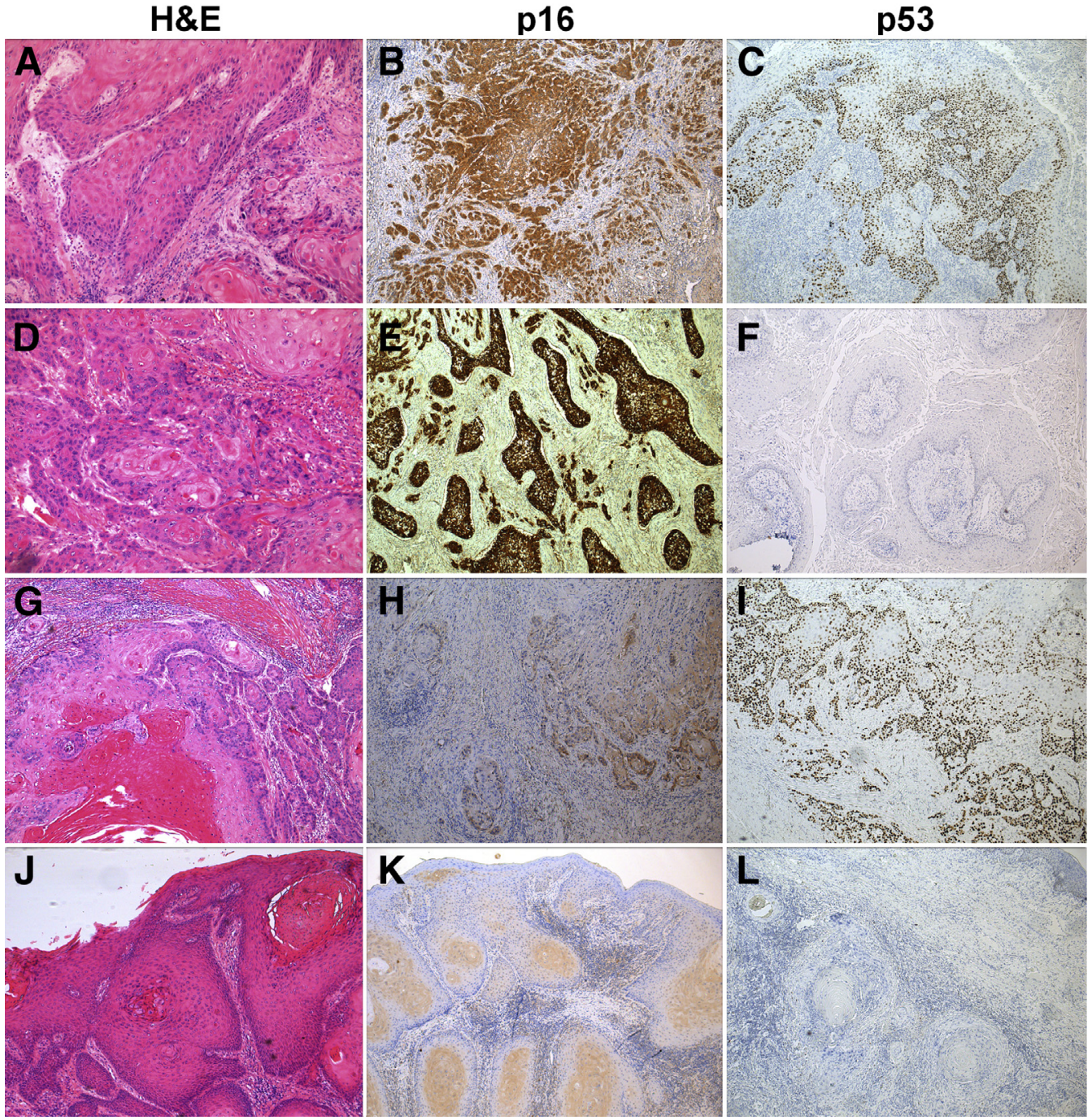

Figure 1 Marker expression in penile squamous cell carcinoma (PSCC). Four patterns of p16 and p53 marker expression are shown, with corresponding histology (hematoxylin and eosin (H\&E) stain). A-C: One group of PSCCs shows positive immunoreaction for both p16 $6^{\text {INK4a }}$ (B) and p53 (C). D-I: In the second and third groups, PSCCs exhibit a mutually exclusive immunolabeling of p16 ${ }^{\text {INK4a }}$ (E and $\mathbf{H}$ ) and p53 (F and I). J-L: Lastly, some PSCCS are double negative ( $\mathbf{K}$ and $\mathbf{L})$. Original magnification: $\times 40(\mathbf{A}$ and $\mathbf{D}) ; \times 100(\mathbf{B}, \mathbf{C}$, and $\mathbf{E}-\mathbf{L})$.

using a BigDye Terminator version 1.1 cycle sequencing kit (Life Technologies).

\section{Statistical Analysis}

The correlation between continuous variables was computed as Pearson's $r$. Nonparametric testing ( $U$-test) was used to study differences between miRNA amounts for condyloma and PSCC cases, among PSCC cases positive and negative for HPV16, and among PSCC cases positive and negative for $\mathrm{p} 16^{\mathrm{INK} 4 \mathrm{a}}$ and $\mathrm{p} 53$. In addition, levels of within-sample agreement between HPV type and $\mathrm{p} 16^{\mathrm{INK} 4 \mathrm{a}}$ expression were assessed by $\chi^{2}$ test. $P<0.05$ was considered statistically significant. All statistical analyses were performed using $\mathrm{R}$ software version 2.9 (R Foundation for Statistical Computing, Vienna, Austria). Data are expressed as means $\pm \mathrm{SD}$, as median and range, or as percentages for categorical variables.

\section{Results}

\section{Histological Findings}

The PSCC specimens exhibited a wide spectrum of microscopic findings (Figure 1). Overall, the 59 specimens (54 invasive and 5 in situ) exhibited a classic squamous appearance; the series covered the full range from well to poorly differentiated (although the majority had a moderate degree of differentiation and keratinization). In two of the poorly differentiated PSCCs, a comedo-like necrosis was observed. Invasion presented as individual cells or as sheets and nests of atypical cells. A verrucous feature was present in 10 PSCCs, with papillomatous growth and hyperparakeratosis with low to moderate grade tumor cells and common koilocytosis. Finally, four PSCCs exhibited a basaloid appearance, with tightly closed tumor cell nests always associated with comedo-type necrosis. These cells were small, with scant 
Table 2 Results of HPV Detection and Typing and of p16 ${ }^{\text {INK4a }}$, p53, and Ki-67 Immunostaining in PSCC and Control Specimens

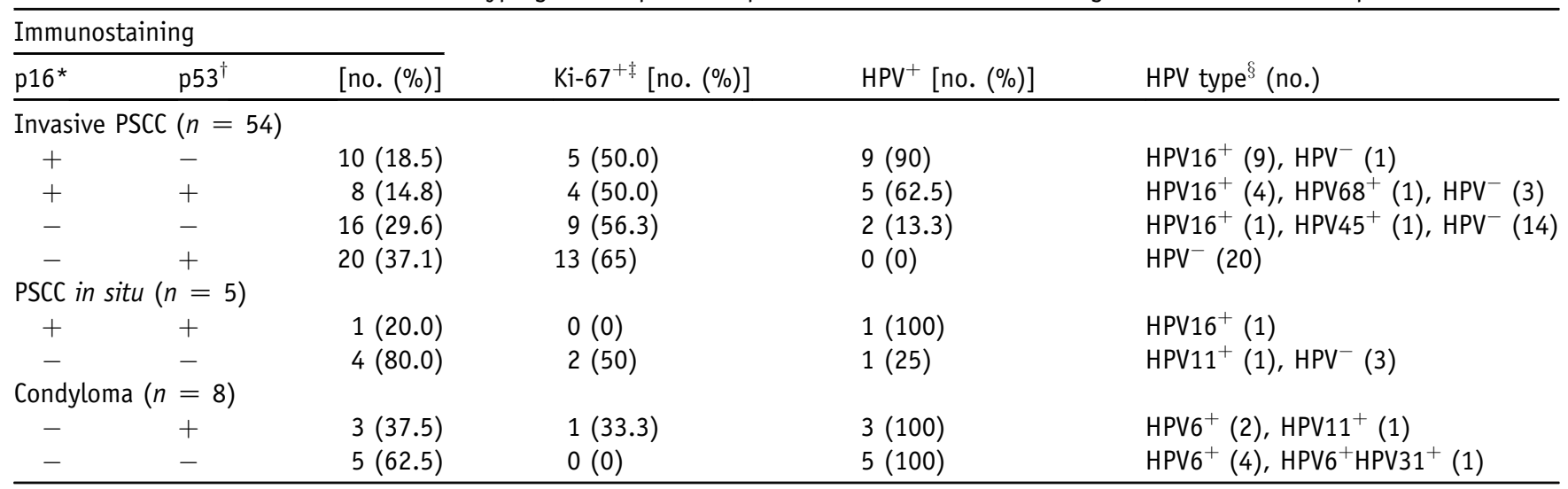

${ }^{*} \mathrm{p} 16^{\mathrm{INK} 4 \mathrm{a}}$ positivity is defined as pattern 3 staining: dense and continuous cytoplasmic/nuclear staining in all neoplastic cells (except hyperkeratotic or parakeratotic areas)..$^{10}$

${ }^{\dagger} \mathrm{p} 53$ positivity is defined as $\mathrm{p} 53$ nuclear staining in $\geq 75 \%$ of the cells.

${ }^{\ddagger} \mathrm{Ki}-67$ positivity is defined as immunoreaction in $>60 \%$ of cells. ${ }^{11}$

${ }^{\S}$ High risk: HPV16, HPV31, HPV45, and HPV68. Low risk: HPV6, HPV11.

HPV, human papillomavirus; PSCC, penile squamous cell carcinoma.

cytoplasm, oval or round nuclei, and inconspicuous nucleoli. Condylomata presented complex papillary arrangements of squamous epithelium in association with vacuolization of keratinocytes and enlarged, hyperchromatic, and folded nuclei (koilocytosis), along with stromal lymphocytic infiltration.

\section{HR-HPV Detection}

The presence of HPV infection in penile specimens was investigated by line probe assay and HPV type-specific realtime PCR. Specimens were considered $\mathrm{HPV}^{+}$if HPV DNA copy number was greater than 1 genome equivalent per cell, consistent with a clonal expansion of $\mathrm{HPV}^{+}$cancer cells.
These stringent criteria were chosen to differentiate pathogenic HPV types from co-infecting or contaminating HPV types, which may be present in cancer tissues. According to these criteria, HPV DNA was detected in two of five (40\%) cases of PSCC in situ and in 16/54 (30\%) cases of invasive PSCC (Table 2). Overall, $17 / 59$ (29\%) PSCCs were positive for HR-HPV (Table 3). All eight penile condylomata were positive for low-risk HPV6 or HPV11. Estimation of HPV DNA copy number in PSCCs by qPCR indicated the presence of approximately 1 to 100 genome equivalents per cell. The presence of HR-HPV infection was detected in $3 / 4$ (75\%) basaloid PSCCs, 2/10 (20\%) verrucous PSCCs, and 2/6 (33\%) grade 3 PSCCs (Table 3).

Table 3 Histopathological Findings in PSCCs According to HR-HPV Detection and Biomarker Expression

\begin{tabular}{|c|c|c|c|c|c|c|c|}
\hline \multirow[b]{2}{*}{ Feature } & \multirow[b]{2}{*}{$\operatorname{PSCC}[$ no. $(\%)]$} & \multicolumn{3}{|c|}{ Subtype [no. (\%)] } & \multicolumn{3}{|c|}{ Grade [no. (\%)] } \\
\hline & & WD & Basaloid & Verrucous & 1 & 2 & 3 \\
\hline \multicolumn{8}{|l|}{ HR-HPV } \\
\hline+ & $17(28.8)$ & $12(20.3)$ & $3(5.1)$ & $2(3.4)$ & $9(15.3)$ & $6(10.2)$ & $2(3.4)$ \\
\hline \multicolumn{8}{|c|}{ p16 ${ }^{\text {INK4a }}$ pattern $^{\dagger}$} \\
\hline 0 & $18(30.5)$ & $13(22.0)$ & $1(1.7)$ & $4(6.8)$ & $3(5.1)$ & $12(20.3)$ & $3(5.1)$ \\
\hline 3 & $19(32.2)$ & $13(22.0)$ & $3(5.1)$ & $3(5.1)$ & $10(16.9)$ & $7(11.9)$ & $2(3.4)$ \\
\hline \multicolumn{8}{|l|}{$\mathrm{p} 53^{\ddagger}$} \\
\hline- & $29(49.2)$ & $21(35.6)$ & $2(3.4)$ & $6(10.2)$ & $15(25.4)$ & $12(20.3)$ & $2(3.4)$ \\
\hline+ & $30(50.8)$ & $24(40.7)$ & $2(3.4)$ & $4(6.8)$ & $8(13.6)$ & $18(30.5)$ & $4(6.8)$ \\
\hline Total & $59(100)$ & $45(76.3)$ & $4(6.8)$ & $10(16.9)$ & $21(35.6)$ & $32(54.2)$ & $6(10.2)$ \\
\hline
\end{tabular}

${ }^{*}$ Of the 42 cases lacking HR-HPV infection, 1 was positive for HPV11.

${ }^{\dagger} p 16^{\text {INK4a }}$ immunostaining pattern: 0 , complete absence of $p 16^{\text {INK4a }}$ staining in all of the neoplastic cells; 1 , staining only in isolated and dispersed neoplastic cells; 2 , staining in patchy and scattered clusters of neoplastic cells; and 3, dense and continuous cytoplasmic/nuclear staining in all neoplastic cells (except hyperkeratotic or parakeratotic areas). ${ }^{10}$

${ }^{\ddagger} \mathrm{p} 53$ positivity is defined as $\mathrm{p} 53$ nuclear staining in $\geq 75 \%$ of the cells.

HR-HPV, high-risk human papilloma virus; WD, well differentiated. 


\section{Expression of p16 ${ }^{\mathrm{INK} 4 \mathrm{a}}, \mathrm{p} 53$, and Ki-67}

Overexpression of p16 ${ }^{\mathrm{INK} 4 \mathrm{a}}$ (Figure 1) (ie, pattern 3, as described above and in Ref. 10), which is a considered a surrogate biomarker of HR-HPV infection, was identified in 19/59 (32\%) PSCCs (Table 3) and was significantly associated with the presence of HR-HPV infection $(P<0.001$, $\chi^{2}$ test), with sensitivity of $88 \%$ and specificity of $95 \%$. Interestingly, $\mathrm{p} 16^{\mathrm{INK} 4 \mathrm{a}}$ overexpression seemed to be associated, although not significantly, with the presence of basaloid features and with low histological grading (grades 1 and 2) (Table 3). Because this observation is based on few PSCCs, it should be confirmed by further studies involving an adequate number of cases.

p53 immunoreactivity was detected in 30/59 (51\%) PSCCs. No significant correlation was observed between p53 expression and HR-HPV infection, p16 ${ }^{\mathrm{INK} 4 \mathrm{a}}$ immunostaining, and histological features (Figure 1); $\mathrm{p}^{+} 3^{+}$immunostaining was more frequently observed in grade 2 and grade 3 PSCCs than in grade 1 PSCCs (Table 3 ).

Immunostaining for the proliferation marker Ki-67 was also investigated in penile specimens. No relationship was observed between the percentage of $\mathrm{Ki}-67^{+}$cells and histological features, HR-HPV infection, or $\mathrm{p} 16^{\mathrm{INK} 4 \mathrm{a}}$ and $\mathrm{p} 53$ immunostaining.

\section{miRNA Expression}

Expression of a panel of miRNAs (let-7c, miR-34a, miR23b, miR-145, miR-146a, miR-196a, and miR-218) was investigated by RT-qPCR in all samples. The panel was selected based on literature indicating an association with HPV16 infection and/or cervical carcinoma. ${ }^{6,17-22}$ Expression of miR-218 showed a downward trend in PSCCs with HR-HPV infection $(P=0.069)$, and it was down-regulated in p53- PSCCs $(P=0.011)$. In the subgroup of HR-HPV ${ }^{-}$ PSCCs, expression of miR-218 was significantly lower in $\mathrm{p} 53^{-}$than $\mathrm{p} 53^{+}$PSCCs $(P=0.020)$; no difference in miR218 expression was observed between $\mathrm{p} 53^{+}$and $\mathrm{p} 53^{-}$tumors in the HR-HPV ${ }^{+}$PSCC group (Figure 2A). miR-218 expression levels were similar among HR-HPV ${ }^{+}$cases and those lacking both p53 immunolabeling and HR-HPV infection.

Levels of miR-23b, miR-145, and miR146a were lower in $\mathrm{HR}^{-\mathrm{HPV}^{+}}$(and $\mathrm{p} 16^{\mathrm{INK} 4 \mathrm{a}+}$ ) $\mathrm{PSCCs}$ than in $\mathrm{HR}^{-\mathrm{HPV}^{-}}$ PSCCs, although the difference was not statistically significant (Figure 2B). No association was observed between these miRNAs and p53 or Ki-67 expression and histological features, except that miR-196a levels were significantly higher $(P<0.05)$ in grade 2 and 3 PSCCs than in grade 1 PSCCs (relative expression: $3.0 \pm 5.6$ versus $1.0 \pm 0.6$, respectively).

\section{SLIT2 and SLIT3 Promoter Methylation}

Because promoter hypermethylation has been reported to be a common mechanism of miR-218 down-regulation in
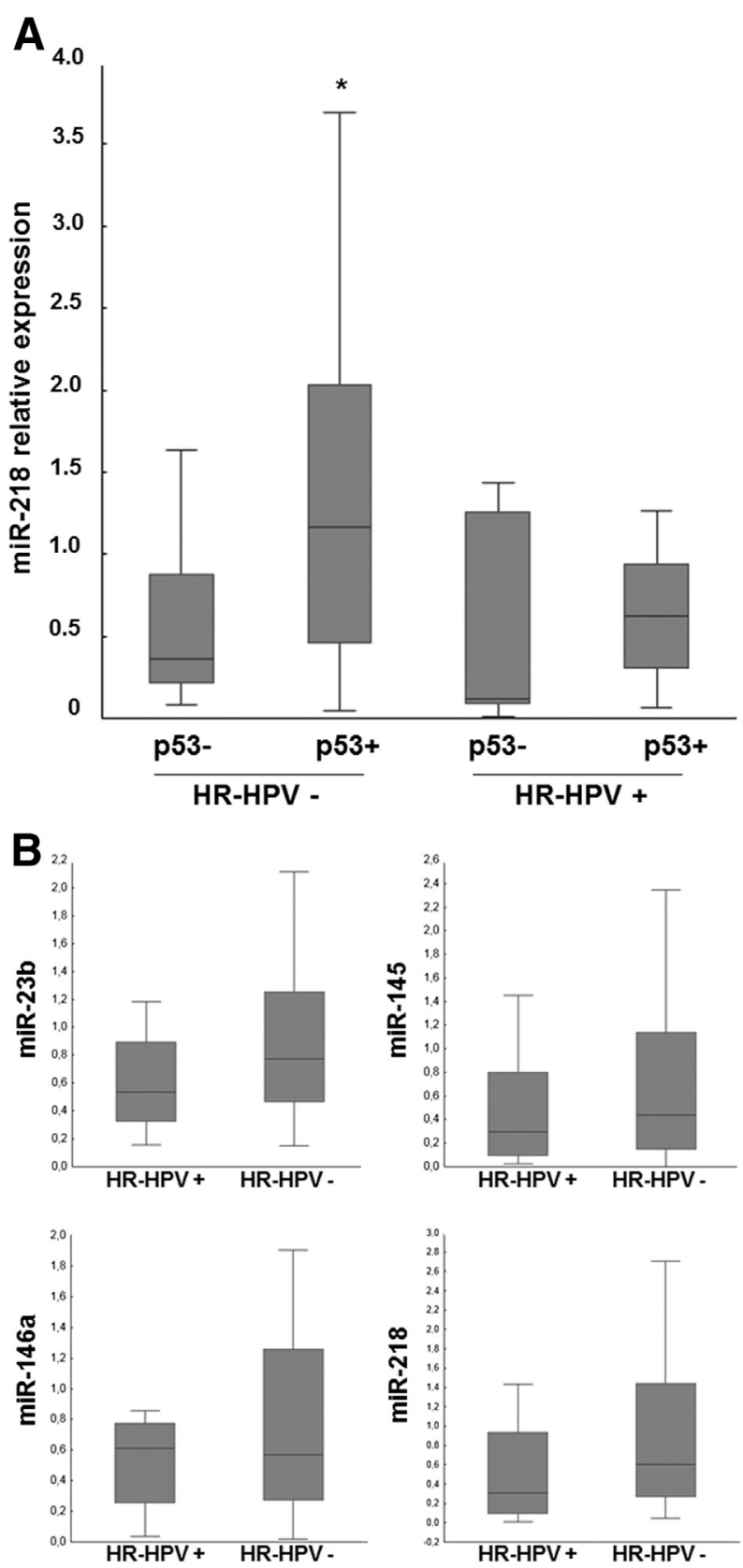

Figure 2 Expression of miRNA in PSCC. A: Median values of miR-218 in PSCCs according to high-risk human papillomavirus (HR-HPV) status and p53 immunostaining. B: Median values of four miRNAs in PSCCs according to HR-HPV status. miRNA levels were measured by real-time quantitative $P C R$ with reverse transcription using the $2^{-\Delta \Delta C t}$ method; tests were performed in triplicate and normalized to RNA U6B values. Data are expressed as box-and-whisker plots, indicating median, interquartile range, and minimum and maximum values on a logarithmic scale. ${ }^{*} P<0.05$.

several cancers, including oral $\mathrm{SCCs},{ }^{23}$ we performed methylation analysis of the promoter of SLIT2 and SLIT3 (tumor suppressor genes that respectively contain the miR218-1 and miR-218-2 precursors in the intronic region), using a methylation-specific PCR method that qualitatively assesses the presence of a hypermethylated $\mathrm{CpG}$ island in the promoters. ${ }^{16}$ For SLIT2, both methylated and unmethylated alleles were detected in tumor samples by PCR, 


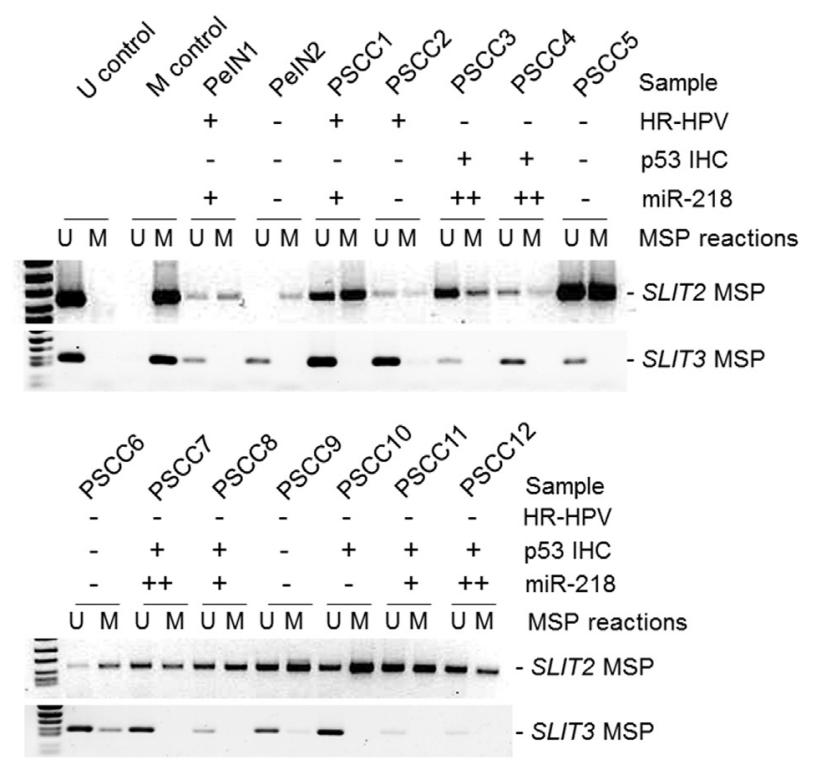

Figure 3 Representative results of methylation-specific PCR (MSP) of SLIT2 and SLIT3 promoters in PSCC in situ (PeIN) and in invasive PSCC according to HR-HPV detection, p53 immunostaining, and miR-218 expression. IHC, immunohistochemistry; $M$, methylated; U, unmethylated.

indicating partial methylation. However, in tumors with low miR-218 levels, the degree of promoter methylation was greater than in those with higher miR-218 levels (Figure 3). Sequence analysis of methylation-specific PCR amplicons of the SLIT2 promoter confirmed the presence of methylated CpG sites. For SLIT3, only unmethylated alleles were observed (Figure 3).

\section{Discussion}

In this retrospective study, we investigated expression of a group of miRNAs associated with HPV-related cancer on a series of PSCCs and correlated miRNA expression with the presence of HPV infection, with $\mathrm{p} 16^{\mathrm{INK} 4 \mathrm{a}}, \mathrm{p} 53$, and Ki-67 immunostaining, and with pathological features. The main finding of the present study is the demonstration that miR218 was significantly down-regulated in $\mathrm{p}^{-} 3^{-}$PSCCs. This finding was confirmed among HR-HPV ${ }^{-}$cancers. Interestingly, miR-218 expression showed a downward trend in $\mathrm{HR}_{-} \mathrm{HPV}^{+}$PSCCs, compared with $\mathrm{HR}^{-\mathrm{HPV}^{-}}$ PSCCs. Moreover, among HR-HPV ${ }^{+}$cases the expression levels of miR-218 were similar to those cases lacking both p53 immunolabeling and HR-HPV infection, irrespective of p53 expression. In addition, by using stringent criteria to define $\mathrm{HPV}^{+}$tumors, we demonstrated the presence of HRHPV infection in approximately one third of PSCCs and confirmed the significant association between HR-HPV infection and $\mathrm{p} 16^{\mathrm{INK} 4 \mathrm{a}}$ overexpression.

Our results on miR-218 expression in PSCCs are consistent with the literature on other HPV-related cancers. miR-218 has been shown to be significantly down-regulated in cervical carcinoma cell lines and in cervical tissues containing HPV16, compared with the normal cervix, ${ }^{19,24}$ as well as in HR-HPV ${ }^{+}$head and neck SCCs, compared with HR-HPV ${ }^{-}$cancers. $^{25}$ The E6 gene of high-risk HPV16 (but not of low-risk HPV6) reduced expression of both miR218 and of SLIT2, which contains miR-218-1 sequence in its intronic region. ${ }^{19}$ miR-218 deregulation by E6 in HPVrelated cancers has been suggested to occur via promoter hypermethylation of the SLIT2 gene. ${ }^{26}$ However, miR-218 has been found to be underexpressed also in $\mathrm{HPV}^{-}$oral SCC, and the mechanism of silencing was again through promoter hypermethylation, ${ }^{23}$ thus indicating that promoter hypermethylation is a common mechanism of miR-218 silencing in SCCs. In the present study, methylation of the SLIT2 promoter was observed in both $\mathrm{HR}-\mathrm{HPV}^{+}$and HR$\mathrm{HPV}^{-}$PSCCs, and the degree of promoter methylation correlated with miR-218 silencing. In three cases, however, we observed equal signals for methylated and unmethylated promoter DNA. Such findings suggest the possibility that other mechanisms (eg, chromatin structure in the promoter region) may play an important role in the regulation of miR218 expression in addition to DNA methylation. Furthermore, our findings identify miR-218 down-regulation as an important event in PSCC oncogenesis, which in $\mathrm{p}^{+} 3^{+}$cases could be related to a HR-HPV effect.

Hypermethylation of the promoter of the SLIT3 gene, which contains miR-218-2 in its intronic region, has been also reported in different cancers, but less frequently than hypermethylation of the SLIT2 promoter. ${ }^{23,27}$ Indeed, all of the cases analyzed in the present study were unmethylated. miR-218 has antiproliferative and proapoptotic activity in vitro. ${ }^{23,26}$ Several cell targets have been identified for this miRNA, including ROBOI, PXN, and LASPI, ${ }^{26,28}$ which are implicated in tumor invasion and metastasis, and the mTOR component RICTOR, ${ }^{23}$ which has antiproliferative activity. Moreover, the SLIT2 gene has tumor suppressor activity and, together with $\mathrm{pRb}$ and $\mathrm{p} 53$, is frequently mutated, inactivated, or down-regulated in human cancer, indicating its driving role in oncogenesis. ${ }^{29}$ In the present study, expression of miR-218 was lower in HR-HPV ${ }^{+}$ PSCCs and in HR-HPV ${ }^{-}$PSCCs without p53 immunostaining than in those positive for p53. This suggests that miR-218 is down-regulated independently of p53 and might represent an important molecular event in penile oncogenesis, in addition to HR-HPV transformation and p53 inactivation.

We also addressed HPV detection and typing in penile tumors and correlation with biomarkers. In accord with the literature, ${ }^{2-4}$ HPV16 was the most commonly found HRHPV type, confirming the relevant role of this HPV type in penile carcinogenesis. In our series of 54 invasive PSCC cases, one was $\mathrm{HPV}^{+} 5^{+}$and another was $\mathrm{HPV}^{+} 8^{+}$ (Table 2). In addition to HPV infection, other underlying molecular mechanisms of carcinogenesis are suggested by the negative $\mathrm{p} 16^{\mathrm{INK} 4 \mathrm{a}}$ immunostaining in the $\mathrm{HPV}^{\mathrm{I}} 5^{+}$case and p53 overexpression in the HPV $68^{+}$case. Although p16 $6^{\mathrm{INK} 4 \mathrm{a}}$ protein expression was a very good marker of 
HR-HPV infection in PSCCs, p53 immunostaining did not correlate with HR-HPV infection, which is in accord with previous report. ${ }^{30}$ Stratification of PSCCs according to HRHPV infection, $\mathrm{p} 16^{\mathrm{INK} 4 \mathrm{a}}$ and $\mathrm{p} 53$ immunostaining, tumor grade, and tumor subtype demonstrated that tumors with HRHPV infection overexpressed $\mathrm{p} 16^{\mathrm{INK} 4 \mathrm{a}}$, were lower grade, and in some cases were characterized by basaloid features, whereas $\mathrm{p} 53^{+}$immunostaining was more common in cases with high histological grade. In this regard, $\mathrm{p} 16^{\mathrm{INK} 4 \mathrm{a}}$ overexpression and HR-HPV infection are considered markers of good prognosis in PSCC, ${ }^{31,32}$ whereas p53 expression predicts poor prognosis. ${ }^{33}$ Basaloid PSCCs are usually associated with a worse prognosis. ${ }^{7}$ Interestingly, in our series $3 / 4$ basaloid cases were $\mathrm{HR}-\mathrm{HPV}^{+}$, which should have indicated a better prognosis; however, two of these cases were also $\mathrm{p} 53^{+}$, which could explain the generally worse outcome of this subtype of PSCCs. This issue should be further addressed in a numerically appropriate series of basaloid PSCCs.

Here, we have reported for the first time the analysis of miRNA expression in PSCC. miR-218 was significantly down-regulated in $\mathrm{HR}^{-\mathrm{HPV}^{+}}{ }^{\mathrm{PSCC}}$ and in those without immunohistochemical detection of p53 as a consequence of epigenetic silencing of the SLIT2 promoter. Silencing of miR-218 and SLIT2 appears to be an important molecular event involved in PSCC and SCC oncogenesis.

\section{References}

1. Pizzocaro G, Algaba F, Horenblas S, Solsona E, Tana S, Van Der Poel H, Watkin NA; European Association of Urology (EAU) Guidelines Group on Penile Cancer: EAU penile cancer guidelines 2009. Eur Urol 2010, 57:1002-1012

2. Miralles-Guri C, Bruni L, Cubilla AL, Castellsagué X, Bosch FX, de Sanjosé S: Human papillomavirus prevalence and type distribution in penile carcinoma. J Clin Pathol 2009, 62:870-878

3. Backes DM, Kurman RJ, Pimenta JM, Smith JS: Systematic review of human papillomavirus prevalence in invasive penile cancer. Cancer Causes Control 2009, 20:449-457

4. Cubilla AL, Lloveras B, Alejo M, Clavero O, Chaux A, Kasamatsu E, Velazquez EF, Lezcano C, Monfulleda N, Tous S, Alemany L, Klaustermeier J, Muñoz N, Quint W, de Sanjose S, Bosch FX: The basaloid cell is the best tissue marker for human papillomavirus in invasive penile squamous cell carcinoma: a study of 202 cases from Paraguay. Am J Surg Pathol 2010, 34:104-114

5. Moody CA, Laimins LA: Human papillomavirus oncoproteins: pathways to transformation. Nat Rev Cancer 2010, 10:550-560

6. Zheng ZM, Wang X: Regulation of cellular miRNA expression by human papillomaviruses. Biochim Biophys Acta 2011, 1809:668-677

7. Eble JN, Sauter G, Epstein JI, Sesterhenn IA (Eds): Pathology and Genetics of Tumours of the Urinary System and Male Genital Organs. World Health Organization Classification of Tumours. Lyon, IARC press, 2004, pp 279-298

8. Fassina A, Cappellesso R, Guzzardo V, Dalla Via L, Piccolo S, Ventura L, Fassan M: Epithelial-mesenchymal transition in malignant mesothelioma. Mod Pathol 2012, 25:86-99

9. Rosato A, Menin C, Boldrin D, Santa SD, Bonaldi L, Scaini MC, Del Bianco P, Zardo D, Fassan M, Cappellesso R, Fassina A: Survivin expression impacts prognostically on NSCLC but not SCLC. Lung Cancer 2013, 79:180-186

10. Cubilla AL, Lloveras B, Alejo M, Clavero O, Chaux A, Kasamatsu E, Monfulleda N, Tous S, Alemany L, Klaustermeier J, Muñoz N,
Quint W, de Sanjose S, Bosch FX: Value of p16(INK)(4)(a) in the pathology of invasive penile squamous cell carcinomas: a report of 202 cases. Am J Surg Pathol 2011, 35:253-261

11. Protzel C, Knoedel J, Zimmermann U, Woenckhaus C, Poetsch M, Giebel J: Expression of proliferation marker Ki67 correlates to occurrence of metastasis and prognosis, histological subtypes and HPV DNA detection in penile carcinomas. Histol Histopathol 2007, 22 : 1197-1204

12. Barzon L, Militello V, Pagni S, Palù G: Comparison of INNO-LiPA Genotyping Extra and Hybrid Capture 2 assays for detection of carcinogenic human papillomavirus genotypes. J Clin Virol 2012, 55: 256-261

13. Militello V, Trevisan M, Squarzon L, Biasolo MA, Rugge M, Militello C, Palù G, Barzon L: Investigation on the presence of polyomavirus, herpesvirus, and papillomavirus sequences in colorectal neoplasms and their association with cancer. Int J Cancer 2009, 124: 2501-2503

14. Fassina A, Cappellesso R, Fassan M: Classification of non-small cell lung carcinoma in transthoracic needle specimens using microRNA expression profiling. Chest 2011, 140:1305-1311

15. Fassina A, Cappellesso R, Simonato F, Siri M, Ventura L, Tosato F, Busund LT, Pelizzo MR, Fassan M: A 4-microRNA signature can discriminate primary lymphomas from anaplastic carcinomas in thyroid cytology smears. Cancer Cytopathol 2014, 122:274-281

16. Dallol A, Da Silva NF, Viacava P, Minna JD, Bieche I, Maher ER, Latif F: SLIT2, a human homologue of the Drosophila Slit2 gene, has tumor suppressor activity and is frequently inactivated in lung and breast cancers. Cancer Res 2002, 62:5874-5880

17. Au Yeung CL, Tsang TY, Yau PL, Kwok TT: Human papillomavirus type 16 E6 induces cervical cancer cell migration through the p53/microRNA-23b/urokinase-type plasminogen activator pathway. Oncogene 2011, 30:2401-2410

18. Wang X, Wang HK, McCoy JP, Banerjee NS, Rader JS, Broker TR, Meyers C, Chow LT, Zheng ZM: Oncogenic HPV infection interrupts the expression of tumor-suppressive miR-34a through viral oncoprotein E6. RNA 2009, 15:637-647

19. Martinez I, Gardiner AS, Board KF, Monzon FA, Edwards RP, Khan SA: Human papillomavirus type 16 reduces the expression of microRNA-218 in cervical carcinoma cells. Oncogene 2008, 27: $2575-2582$

20. Lajer CB, Garnaes E, Friis-Hansen L, Norrild B, Therkildsen MH, Glud M, Rossing M, Lajer H, Svane D, Skotte L, Specht L, Buchwald C, Nielsen FC: The role of miRNAs in human papilloma virus (HPV)-associated cancers: bridging between HPV-related head and neck cancer and cervical cancer. Br J Cancer 2012, 106: $1526-1534$

21. Huang L, Lin JX, Yu YH, Zhang MY, Wang HY, Zheng M: Downregulation of six microRNAs is associated with advanced stage, lymph node metastasis and poor prognosis in small cell carcinoma of the cervix. PLoS One 2012, 7:e33762

22. Lee JW, Choi CH, Choi JJ, Park YA, Kim SJ, Hwang SY, Kim WY, Kim TJ, Lee JH, Kim BG, Bae DS: Altered microRNA expression in cervical carcinomas. Clin Cancer Res 2008, 14:2535-2542

23. Uesugi A, Kozaki K, Tsuruta T, Furuta M, Morita K, Imoto I, Omura K, Inazawa J: The tumor suppressive microRNA miR-218 targets the mTOR component Rictor and inhibits AKT phosphorylation in oral cancer. Cancer Res 2011, 71:5765-5778

24. Li Y, Liu J, Yuan C, Cui B, Zou X, Qiao Y: High-risk human papillomavirus reduces the expression of microRNA-218 in women with cervical intraepithelial neoplasia. J Int Med Res 2010, 38 : $1730-1736$

25. Wald AI, Hoskins EE, Wells SI, Ferris RL, Khan SA: Alteration of microRNA profiles in squamous cell carcinoma of the head and neck cell lines by human papillomavirus. Head Neck 2011, 33:504-512

26. Wu DW, Cheng YW, Wang J, Chen CY, Lee H: Paxillin predicts survival and relapse in non-small cell lung cancer by microRNA-218 targeting. Cancer Res 2010, 70:10392-10401 
27. Dickinson RE, Dallol A, Bieche I, Krex D, Morton D, Maher ER, Latif F: Epigenetic inactivation of SLIT3 and SLIT1 genes in human cancers. Br J Cancer 2004, 91:2071-2078

28. Tie J, Pan Y, Zhao L, Wu K, Liu J, Sun S, Guo X, Wang B, Gang Y, Zhang Y, Li Q, Qiao T, Zhao Q, Nie Y, Fan D: miR-218 inhibits invasion and metastasis of gastric cancer by targeting the Robol receptor. PLoS Genet 2010, 6:e1000879

29. Peifer M, Fernández-Cuesta L, Sos ML, George J, Seidel D, Kasper LH, et al: Integrative genome analyses identify key somatic driver mutations of small-cell lung cancer. Nat Genet 2012, 44:1104-1110

30. Stankiewicz E, Prowse DM, Ktori E, Cuzick J, Ambroisine L, Zhang X, Kudahetti S, Watkin N, Corbishley C, Berney DM: The retinoblastoma protein/p16 INK4A pathway but not p53 is disrupted by human papillomavirus in penile squamous cell carcinoma. Histopathology 2011, 58:433-439

31. Lont AP, Kroon BK, Horenblas S, Gallee MP, Berkhof J, Meijer CJ, Snijders PJ: Presence of high-risk human papillomavirus DNA in penile carcinoma predicts favorable outcome in survival. Int J Cancer 2006, 119:1078-1081

32. Gunia S, Erbersdobler A, Hakenberg OW, Koch S, May M: p16(INK4a) is a marker of good prognosis for primary invasive penile squamous cell carcinoma: a multi-institutional study. J Urol 2012, 187 : 899-907

33. Gunia S, Kakies C, Erbersdobler A, Hakenberg OW, Koch S, May M: Expression of p53, p21 and cyclin D1 in penile cancer: p53 predicts poor prognosis. J Clin Pathol 2012, 65:232-236 